\title{
Copiopteryx semiramis (Cramer):notas suplementares à sua biologia (Lepidoptera, Saturniidae, Arsenurinae)
}

\author{
Eurides Furtado ${ }^{1}$
}

\begin{abstract}
Copiopteryx semiramis (Cramer): supplemental notes to its biology (Lepidoptera, Saturniidae, Arsenurinae). The immature stages and the larval hosts of some subspecies of Copiopteryx semiramis (Cramer, 1775) are reported. Egg, larval instars, pupa and adults to the subspecies C. semiramis montei Gagarin, 1933 are illustrated in color for the first time.

KEY WORDS. Saturniidae, Arsenurinae, Copiopteryx, hostplants, immature stages
\end{abstract}

O propósito deste trabalho é reportar e dar subsídios a estudos anteriores sobre a biologia de Copiopteryx semiramis (Cramer, 1775), alguns antigos e de difícil consulta, todos excelentes trabalhos, mas que devido às condições tecnológicas desfavoráveis na época em que foram elaborados não tiveram as ilustrações com a qualidade que pode-se oferecer hoje, e também, as novas informações taxonômicas e etológicas surgidas desde então.

Os estágios imaturos de C. semiramis phoenix (Deyrolle, 1869), do sudeste brasileiro, foram descritos e figurados detalhadamente por TRAVASSOS (1946). As larvas foram criadas em Lucuma caimito Roem. (= Pouteria caimito (Ruiz. \& Pav.) Radlk.) (Sapotaceae), tiveram quatro ínstares no estágio larval, completaram o ciclo de imaturos em 43 dias e o imago emergiu 29 dias depois. Segundo D'ARAUjo E SILVA et al. (1968) as larvas também vivem sobre Acanthosyris spinescens (Mart. \& Eichl.) Gireseb. (Santalaceae).

JANZEN $(1984,1985,1991)$ in WOLFE \& BÉNÉLUZ (1997) listou Manilkara chicle (Pittier) Gilly (Sapotaceae) como a planta hospedeira natural e ilustrou a cores o terceiro ínstar de C. s. banghaasi Draudt, 1930, a subespécie centro-americana, que também foi criada com sucesso (WolfE \& BÉNÉluZ 1997) em Manilkara zapota.

D'AlmeIDA (1975) em trabalho publicado após sua morte, por empenho de Olaf H.H. Mielke, descreveu detalhadamente os estágios imaturos de C. s. montei Gagarin, 1933 a subespécie da grande área dos cerrados do centro-oeste brasileiro. A fêmea mater foi coletada por Nirton Tangerini nas proximidades de Brasília, Distrito Federal. A planta hospedeira não foi mencionada, mas provavelmente R.F. D'Almeida tenha usado Pouteria caimito, planta freqüente nos quintais dos brasileiros e muito utilizada em criações de várias espécies do gênero em estudo. O ciclo evolutivo, da postura ao desenvolvimento dos cinco ínstares larvais, foi de 35 dias. Todas as pupas morreram durante a diapausa.

1) Caixa Postal 97, 78400-000 Diamantino, Mato Grosso, Brasil. 

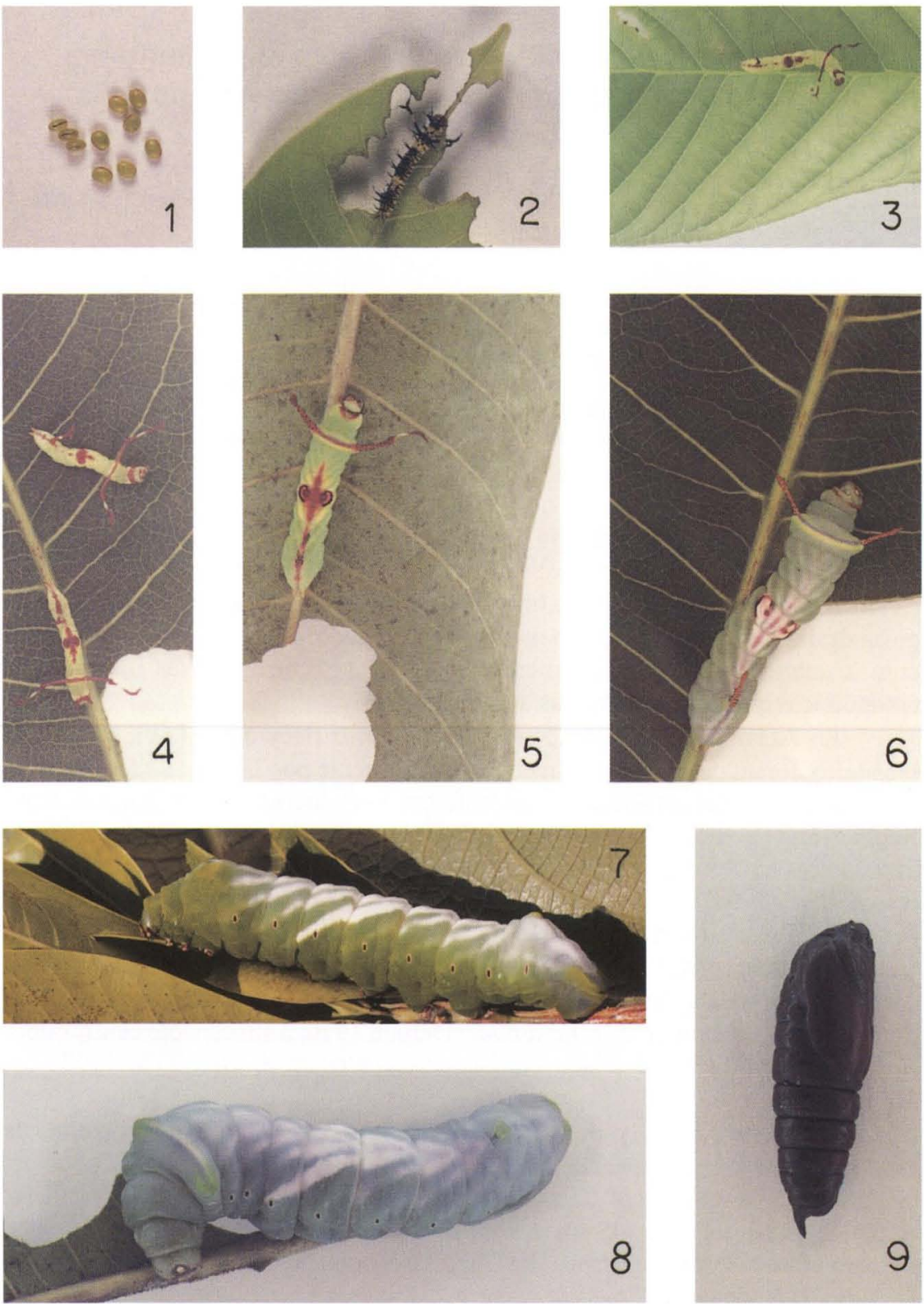

Figs 1-9. Copiopteryx semiramis montei. (1) Ovos; (2) larva de pimeiro instar, vista laterodorsal; (3) larva de segundo instar, vista dorsal; (4) larvas de terceiro instar, vista dorsal; (5) larva de quarto instar, vista dorsal; (6) larva de quinto instar, vista dorsal; (7-8) larvas de sexto instar: (7) vista dorsal, (8) vista laterodorsal; (9) pupa, vista lateral. 


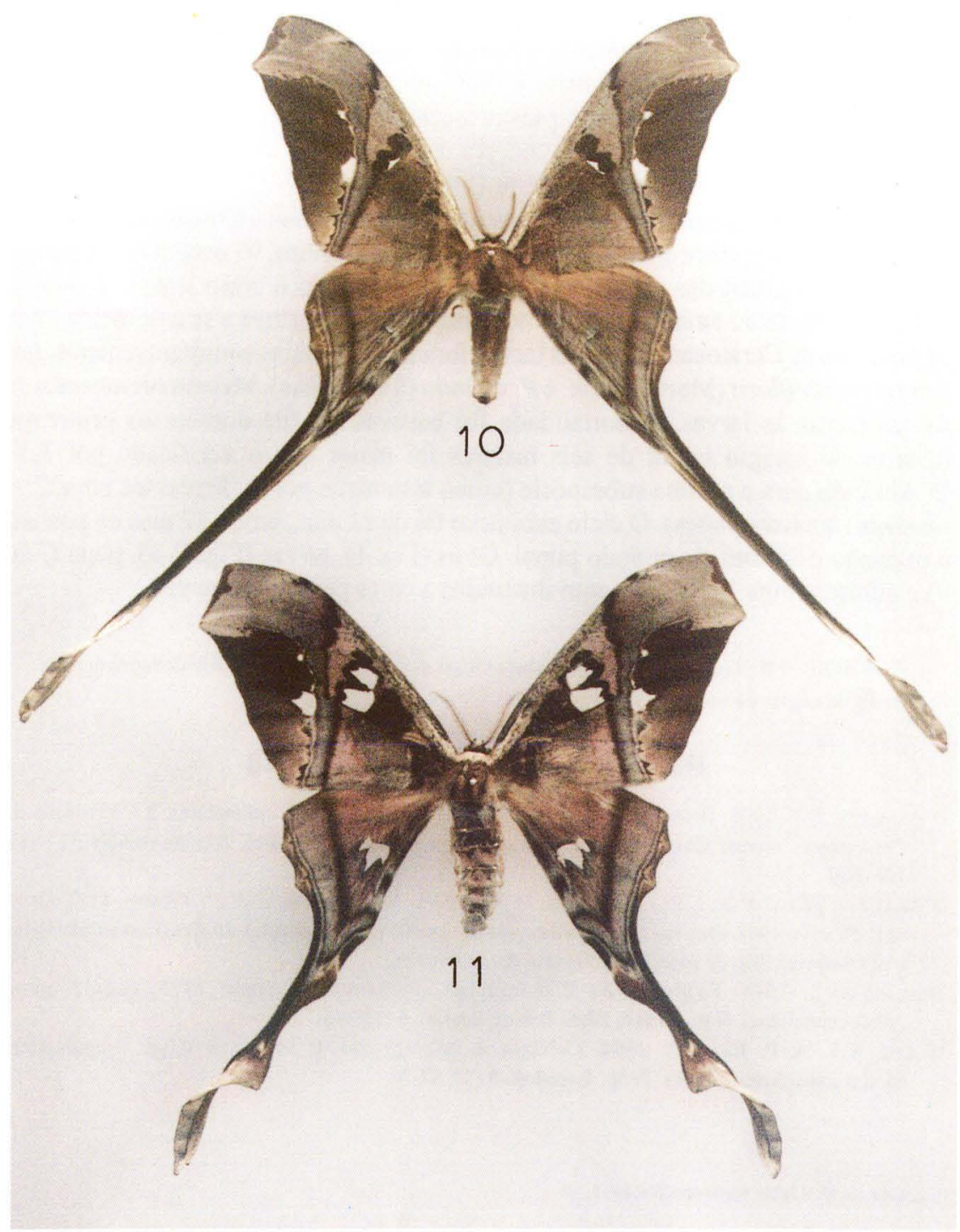

Figs 10-11. Copiopteryx semiramis montei, adultos, vista dorsal: (10) macho (extensão alar $90 \mathrm{~mm}$ ), (11) fêmea (extensão alar $100 \mathrm{~mm}$ ).

Espécie bivoltina, C. s. montei voa na região do Alto Rio Arinos, Diamantino, Mato Grosso, durante a estação chuvosa, com pique de ocorrência no mês de janeiro, se estendendo até março, para mais tarde só reaparecer em outubro-dezembro. Ambos os sexos são atraídos pela luz de lâmpadas mistas e a vapor de mercúrio, sendo os machos muito mais freqüentes, não porque sejam em maior numero, mas porque são mais ativos, mais leves e adequados ao vôo a longas distancias à procura 
de fêmeas virgens, o que aumenta a possibilidade de serem atraídos por um foco luminoso. As fêmeas, mais pesadas e mais lentas, não se afastam muito do local onde nasceram e se o fazem, são presas fáceis de predadores noturnos, sobretudo os morcegos entomófagos, freqüentadores das bordas das matas e da periferia dos focos luminosos, onde sabem encontrar farto alimento.

Para este trabalho foram usadas as posturas de duas fêmeas coletadas em épocas diferentes; da primeira obteve-se 149 ovos; da outra, 95 ovos. O ovo, não só desta, mas também das outras espécies do gênero, com o cório liso, brilhante, e coloração verde ou amarelada, foge ao padrão de Arsenurinae e se assemelha mais às posturas de Ceratocampinae. As larvas foram alimentadas simultaneamente com Pouteria ramiflora (Mart.) Radlk. e P. caimito (Sapotaceae). Mesmo oferecendo-se folhas novas às larvas, a mortalidade foi bastante grande durante os primeiros ínstares. O estágio larval de seis ínstares foi maior que o verificado por R.F. D’Almeida para a mesma subespécie (cinco ínstares) e por L. Travassos para C. s. phoenix (quatro ínstares). O ciclo evolutivo foi de 71 dias, sendo 47 dias da postura à pupação e 24 dias de período pupal. Ovos (Fig. 1), larvas (Figs 2-8), pupa (Fig. 9) e adultos (Figs 10-11) são aqui ilustrados a cores pela primeira vez.

AGRADECIMENTO. Ao Dr. Luiz Soledade Otero, do Museu Nacional do Rio de Janeiro, pelo envio de cópias de literatura.

\section{REFERÊNCIAS BIBLIOGRÁFICAS}

D’AlmeidA, R.F. 1975. Biologia de duas espécies de Saturnioideae (Lepidoptera). 2 - Evolução de Copiopteryx montei Gagarin, 1933, Adelocephalidae. Atas Soc. Biol. Rio de Janeiro 17 (3): 105-109.

D’Araujo e Silva, A.G.; C.R. Gonçalves; D.M. Galvão; A.J.L. Gonçalves; J. Gomes; M.N. Silva \& L. SIMONI. 1968. Quarto catálogo dos insetos que vivem nas plantas do Brasil, seus parasitos e predadores. Rio de Janeiro, Ministério da Agricultura.

Travassos, L. 1946. Evolução de "Copiopteryx semiramis" (Cramer, 1775) (Lepidoptera, Adelocephalidae). Rev. Brasil. Biol., Rio de Janeiro, 6 (1): 1-6.

WolfE, K.L. \& F. BÉNÉluz. 1997. Copiopteryx jehovah and its immature stages (Lepidoptera: Saturniidae: Arsenurinae). Trop. Lepidop. 8 (2): 67-70.

Recebido em 18.V.2000; aceito em 08.V.2001. 